\title{
Targeting Astrocyte Signaling for Chronic Pain
}

\author{
Yong-Jing Gao and Ru-Rong Ji \\ Department of Anesthesiology, Sensory Plasticity Laboratory, Pain Research Center, Brigham and Women's Hospital and \\ Harvard Medical School, Boston, Massachusetts 02115
}

\begin{abstract}
Summary: Clinical management of chronic pain after nerve injury (neuropathic pain) and tumor invasion (cancer pain) is a real challenge due to our limited understanding of the cellular mechanisms that initiate and maintain chronic pain. It has been increasingly recognized that glial cells, such as microglia and astrocytes in the CNS play an important role in the development and maintenance of chronic pain. Notably, astrocytes make very close contacts with synapses and astrocyte reaction after nerve injury, arthritis, and tumor growth is more persistent than microglial reaction, and displays a better correlation with chronic pain behaviors. Accumulating evidence indicates that activated astrocytes can release proinflammatory cytokines (e.g., interleukin [IL]-1 $\beta$ ) and chemokines (e.g., monocyte chemoattractant protein-1 [MCP-1]/ also called CCL2) in the spinal cord to enhance and prolong persistent pain states. IL- $1 \beta$ can powerfully modulate synaptic
\end{abstract}

transmission in the spinal cord by enhancing excitatory synaptic transmission and suppressing inhibitory synaptic transmission. IL- $1 \beta$ activation (cleavage) in the spinal cord after nerve injury requires the matrix metalloprotease-2. In particular, nerve injury and inflammation activate the c-Jun N-terminal kinase in spinal astrocytes, leading to a substantial increase in the expression and release of MCP-1. The MCP-1 increases pain sensitivity via direct activation of NMDA receptors in dorsal horn neurons. Pharmacological inhibition of the IL- $1 \beta$, c-Jun N-terminal kinase, MCP-1, or matrix metalloprotease-2 signaling via spinal administration has been shown to attenuate inflammatory, neuropathic, or cancer pain. Therefore, interventions in specific signaling pathways in astrocytes may offer new approaches for the management of chronic pain. Key Words: Neuropathic pain, nerve injury, spinal cord, cytokine, chemokine, MAP kinase, glia.

\section{INTRODUCTION}

Pain is an unpleasant sensory experience and normally plays a protective role by warning us of potential harm to our body and enabling us to quickly remove the body part from noxious stimuli, and further learn to avoid them in the long run. When noxious peripheral stimulation is sensed, pain information is mainly transmitted by thin myelinated $\mathrm{A} \delta$ fibers and unmyelinated $\mathrm{C}$ fibers to the dorsal horn in the spinal cord, where second order nociceptive neurons are activated by neurotransmitters, such as glutamate and neuropeptides (e.g., substance P and calcitonin gene-related peptide), which are released from the primary afferents. ${ }^{1}$ The information is further relayed to the thalamus, and it finally reaches the parietal lobe of the cerebral cortex for pain perception. ${ }^{2,3}$ This

Address correspondence and reprint requests to: Ru-Rong Ji or Yong-Jing Gao, Department of Anesthesiology, Brigham and Women's Hospital, 75 Francis St., Medical Research Building, Room 604, Boston, MA 02115. E-mail: rrji@zeus.bwh.harvard.edu or yjing@ zeus.bwh.harvard.edu. type of pain is transient and referred to as acute or physiological pain.

However, under injury conditions, pain can be dissociated from its normal physiological role. It can persist for months to years, even after the original injury or inflammation has largely been healed. This type of pain is called chronic or pathological pain, as the consequence of damage or dysfunction of the peripheral nervous system and CNS (neuropathic pain), peripheral tissue damage or inflammation (inflammatory pain), and tumor invasion (cancer pain). ${ }^{4-6}$ Chronic pain does not convey any useful information. Under injury conditions, painful pressure and thermal stimuli are grossly amplified (hyperalgesia). Even light touch is perceived painful (allodynia). Chronic pain creates considerable suffering for people affected, and it is extremely costly for the individual and for the community, with the estimated cost in the United States alone as more than $\$ 100$ billion every year. $^{7}$

Chronic pain is a maladaptive pain, resulting from the development of neural plasticity in the peripheral sensitization and CNS (central sensitization). ${ }^{8-10}$ It was gen- 
erally believed for a long time that only neurons and their neural circuits were responsible for the development and maintenance of chronic pain, which led to the development of current therapeutics that have been focusing on neuronal targets, including drugs such as NMDA receptor antagonists, selective serotonin/norepinephrine reuptake inhibitors, opioid analgesics, and sodium channel blockers. Although these drugs have shown some effects in some patients, ${ }^{11}$ they often produce a brief pain relief via transient blockade of neurotransmission. Notably, the side effects of these drugs, often CNS-related, such as nausea, sedation, drowsiness, and dizziness, as well as development of analgesic tolerance and addiction after opioid treatment, have greatly limited their universal use. ${ }^{11,12}$ Therefore, research on other means of chronic pain treatment is in urgent demand. As a consequence, studies on non-neuronal cells, especially glial cells in chronic pain conditions, have increased exponentially in the last decade.

Glial cells are 10 to 50 times as numerous as neurons and consist of three major groups: 1) astrocytes, 2) microglia, and 3) oligodendrocytes. ${ }^{13}$ Microglia are the resident macrophage-like cells of the CNS. Oligodendrocytes, which are derived from neuroectoderm, produce myelin to ensheath neuronal axons. Astrocytes are the most abundant cells in term of their number and volume, and they constitute $40 \%$ to $50 \%$ of all glial cells. ${ }^{14}$ In normal conditions, microglia and astrocytes are relatively resting or quiescent; however, see reference. ${ }^{15} \mathrm{Af}-$ ter injury or under disease conditions, they can be converted to reactive states and participate in the pathogenesis of neurological disorders. ${ }^{16-18}$ Increasing evidence has shown that microglia and astrocytes play important roles in the development of chronic pain. ${ }^{18-27}$ Unlike microglia and oligodendrocytes, astrocytes form networks with themselves and are closely associated with neurons and blood vessels. It is estimated that a single astrocyte enwraps 4 to 6 neuronal somata and contacts 300 to 600 neuronal dendrites. ${ }^{28}$ A close contact with neurons and synapses makes it possible for astrocytes to support and nourish neurons, and regulate the external chemical environment of neurons during synaptic transmission. In this review, we will discuss recent progress on astrocyte control of pain.

\section{ASTROCYTE ACTIVATION IN PERSISTENT PAIN CONDITIONS}

Glia activation is emerging as a powerful concept for understanding cellular mechanisms underlying chronic pain. Unfortunately, the term "glia activation" is poorly defined. In the pain research field, astrocyte activation is often referred to glial fibrillary acidic protein (GFAP) upregulation and astrogliosis (hypertrophy of astrocytes, as manifested by enlarged cell bodies and thick pro- cesses). The active astrocytes with gliosis are also called reactive astrocytes. Thus, in the following discussion we refer to this activation state as the reactive state, so as to separate from other activation states. It is well known that after peripheral nerve injury or inflammation or tumor invasion, astrocytes in the CNS (especially the spinal cord) undergo various biochemical, translational, transcriptional, and morphological changes. Therefore, astrocytes could display various activation states after peripheral sensory stimuli and injury. Some activation states occur within minutes, such as increases in intracellular $\mathrm{Ca}^{2+}$ and phosphorylation of signaling molecules. Some activation states occur after tens of minutes (e.g., translational regulation) and hours (e.g., transcriptional regulation). Other activation states may occur after hours or even days, such as astrocyte hypertrophy or astrogliosis.

Astrocyte reaction (GFAP upregulation and hypertrophy) has been found in various injury conditions that are associated with enhanced pain states. These conditions include 1) peripheral nerve injury, such as chronic constriction injury, ${ }^{29}$ spinal nerve ligation (SNL) (FIG. 1), ${ }^{30,31}$ and infraorbital nerve ligation ${ }^{32,33}$; 2) tissue injury/inflammation produced by intraplantar injection of complete Freund's adjuvant, ${ }^{34}$ formalin, ${ }^{35}$ zymosan $^{35}$; and 3) tumor growth in the $\operatorname{skin}^{36-38}$ and bone marrow. ${ }^{39-41} \mathrm{Al}-$ though astrocyte reaction can occur at supraspinal areas, such as the rostral ventramedial medulla after chronic constriction injury of the rat infra-orbital nerve, ${ }^{32,33}$ the forebrain after complete Freund's adjuvant (CFA) injection, ${ }^{34}$ and the gracile nucleus after partial sciatic nerve ligation, ${ }^{42}$ most studies focus on the spinal cord dorsal horn. ${ }^{19}$

Notably, astroglial reaction after nerve injury is more persistent than microglial reaction (e.g., upregulation of the microglial markers CD11b/OX-42 and Iba-1, and hypertrophy of mciroglia). Astroglial reaction can last more than 150 days after nerve injury. ${ }^{43}$ In most cases, microglial reaction precedes astrocytic reaction ${ }^{34,44,45}$ and likely leads to astrocyte reaction. ${ }^{46}$ Interestingly, nerve injury induces an increase in interleukin (IL)-18 and IL-18 receptor in reactive microglia and astrocytes, respectively, in the dorsal horn, suggesting an interaction between microglia and astrocytes in neuropathic pain. ${ }^{47}$ However, astrocyte reaction is not always preceded by microglial reaction. Hald et al ${ }^{40}$ showed that bone cancer resulted in marked spinal astroglial reaction without microglial reaction.

It has been shown that GFAP expression after inflammation or nerve injury requires NMDA receptor ${ }^{48,49}$ and neuronal activity. ${ }^{32,49}$ GFAP expression is also critical for morphological changes of astrocytes (astrogliosis) $)^{34,35}$ and is often correlated with enhanced pain states $^{29,30,50}$; however, see Reference. ${ }^{31}$ Although intrathecal GFAP anti-sense oligonucleotide treatment in 


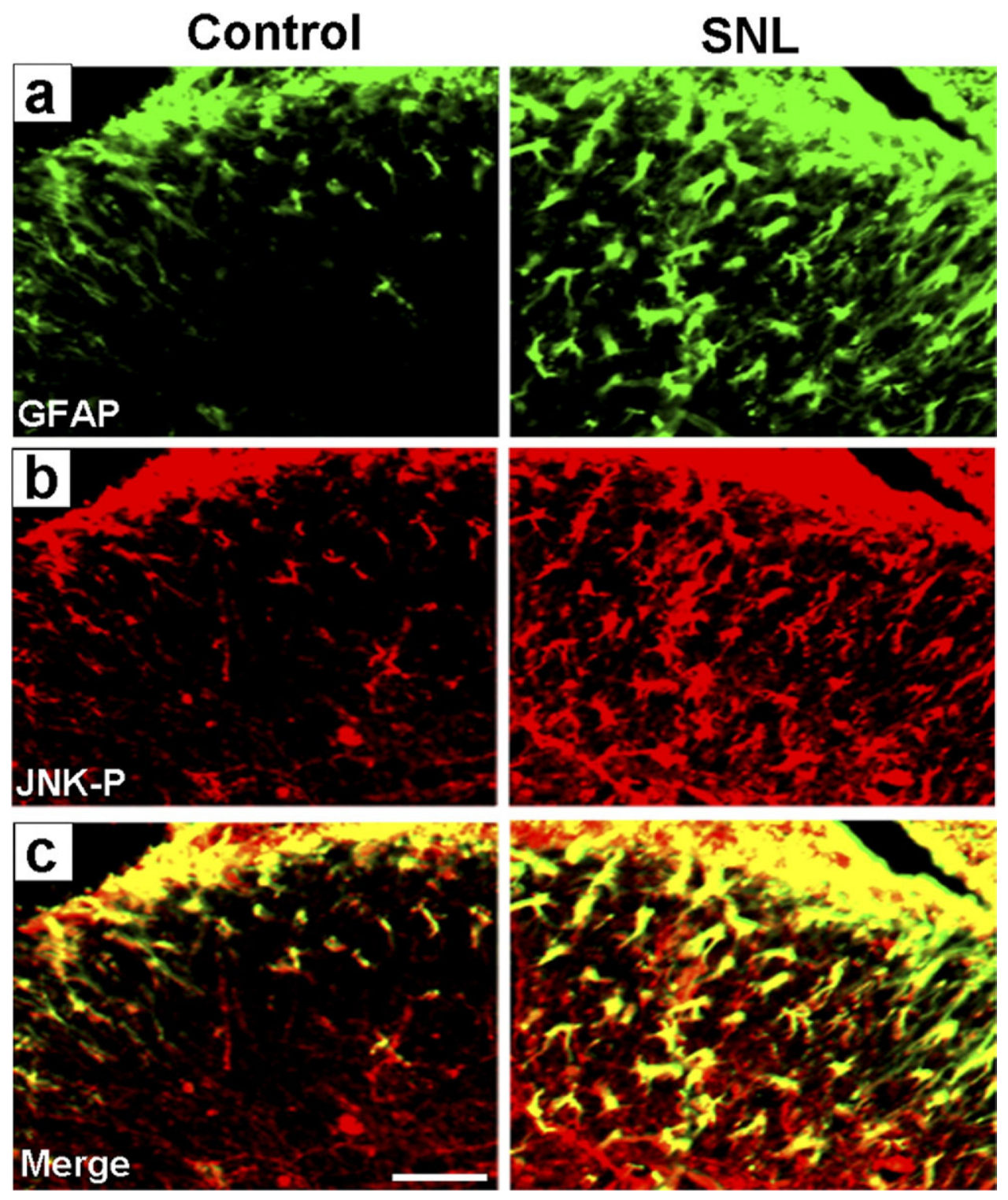

FIG. 1. Spinal nerve ligation induces a substantial increase in C-Jun N-terminal kinase (JNK) phosphorylation and GFAP expression in astrocytes in the spinal cord dorsal horn. Double staining reveals a co-localization of phosphorylated JNK with the astrocyte marker GFAP. Mice were sacrificed 10 days after nerve injury. Contralateral side of the spinal cord is used as the control. (Scale, $50 \mu \mathrm{m}$.)

nerve-injured animals was shown to reduce neuropathic pain behaviors, ${ }^{51}$ this contribution of GFAP to chronic pain could be indirect via unknown mechanisms. It is generally believed that astrocytes control pain states by producing neuromodulators/pain mediators, such as cytokines, chemokines, and growth factors ${ }^{22,32,33,52,53}$ (also see discussion as follows). The production and release of these mediators are not directly controlled by GFAP, rather by some key intracellular signaling pathways, such as the MAP kinase pathway. Remarkably, nerve injury and inflammation induce a persistent phosphorylation of c-Jun N-terminal kinase (JNK) in astrocytes, which may represent a different activation state of astrocytes that is not only correlated with pain hypersensitivity, but also with an underlying cause of this hypersensitivity (FIG. 1). ${ }^{31,54-56}$

\section{ASTROCYTES CONTRIBUTE TO ENHANCED PAIN STATES}

Several lines of evidence suggest that activated astrocytes are sufficient to produce chronic pain symptoms. Hofstetter et al. ${ }^{57}$ reported that implantation of neural stem cells into the injured spinal cord causes allodyniclike hypersensitivity of the forepaws, which is mainly attributed to the conversion of the stem cells into astrocytes. Indeed, the allodynia is prevented when the neural cells are transfected with neurogenin-2 before transplan- 
tation to suppress the generation of astrocytes. ${ }^{57}$ Davies et al. $^{58}$ demonstrated that transplantation of glial-restricted precursor-derived astrocytes promotes the onset of mechanical allodynia. In particular, our recent data showed that intrathecal injection of tumor necrosis factor (TNF)- $\alpha$-activated astrocytes is sufficient to induce the chronic pain hallmark, mechanical allodynia, in naive animals by releasing the chemokine CCL2. ${ }^{59}$

Further studies indicate that astrocytes are also required for the generation of persistent pain. Fluoroacetate and its metabolite fluorocitrate are general inhibitors for glial cells, especially astrocytes. Low doses of fluorocitrate specially disrupt astrocytic metabolism by blocking the glial-specific enzyme aconitase. Intrathecal injection of fluorocitrate or fluoroacetate has been shown to alleviate pain behaviors in animal models of inflammatory pain, neuropathic pain, and postoperative pain. ${ }^{60-65}$ Of interest, fluorocitrate fails to inhibit muscle pain, which a pain condition that does not show obvious glial reaction. ${ }^{66} \mathrm{~L}$-alpha-aminoadipate is another relative specific cytotoxin for astrocytes. ${ }^{67-69}$ Intrathecal injection of L-alpha-aminoadipate produces a dose-dependent attenuation of nerve injury-induced mechanical allodynia. ${ }^{31,70}$

There is an increasing list of signaling molecules in astrocytes that have been implicated in persistent pain (Table 1). The glial glutamate transporter-1 is abundantly expressed in astrocytes ${ }^{71}$ and contributes to the clearance of glutamate from synaptic clefts and the extracellular space. ${ }^{72,73}$ The altered expression and function of glutamate transporters could modulate glutamatergic trans- mission $^{74,75}$ and neuronal plasticity, such as long-term potentiation. $^{76,77}$ It has been demonstrated that nerve injury induces an initial increase, ${ }^{78,79}$ followed by a persistent decrease of glial glutamate transporter-1 and glutamate-aspartate transporter in the spinal cord. ${ }^{78-81}$ Inhibition of glutamate transporters causes an elevation in spinal extracellular glutamate concentrations and elicits spontaneous nociceptive behaviors and hypersensitivity to mechanical and thermal stimuli. ${ }^{82,83}$ Gene transfer of glial glutamate transporter-1 into the spinal cord has no effect on acute mechanical and thermal nociceptive responses in naive animals, but it attenuates inflammatory and neuropathic pain. ${ }^{84}$ These studies indicate a potential role of astroglial glutamate transporters in the recovery of chronic pain. However, the role of glutamate transporters in persistent inflammatory pain conditions could be different, because these transporters are not downregulated after inflammation. Trigeminal pain after tooth pulp inflammation is attenuated by intrathecal superfusion of methionine sulfoximine, an inhibitor of the astroglial enzyme glutamine synthetase, which is involved in the glutamate-glutamine shuttle. ${ }^{85}$

Astrocytes express proteases, such as tissue-type plasminogen activator (tPA) and matrix metalloproteases (MMP) that may be critical for the cleavage and release of signaling molecules from astrocytes. tPA is an extracellular serine protease and converts the plasminogen into the serine protease plasmin. Kozai et al. ${ }^{86}$ showed that L4/5 root injury induces marked induction of tPA in activated astrocytes and a resultant increase of proteolytic enzymatic activity in the dorsal horn. Moreover,

Table 1. Signaling Molecules in Astrocytes

\begin{tabular}{llll}
\hline Signaling Molecule & $\begin{array}{c}\text { Changes in Chronic } \\
\text { Pain Conditions }\end{array}$ & Role in Chronic Pain & Reference No. \\
\hline ALXR & Upregulation & Inhibition & 55 \\
bFGF & Upregulation & Facilitation & 22,102 \\
CCL2/MCP-1 & Upregulation & Facilitation & 52 \\
Connexin-43 & Upregulation & Not tested & 32,96 \\
Endothelin receptor-B & Upregulation & Facilitation & 101 \\
ERK & Upregulation & Not tested & 100 \\
GLAST & Downregulation & Inhibition & 80 \\
GLT-1 & Downregulation & Facilitation & $78-80$ \\
IL-18 receptor & Upregulation & Facilitation & 47 \\
IL-1 $\beta$ & Upregulation & Facilitation & $32,33,41$ \\
MMP-2 & Upregulation & Facilitation & 114 \\
Neurokinin-2 receptor & Not tested & Facilitation & 104 \\
pJNK & Upregulation & Facilitation & $31,36,52$ \\
pNNK1 & Upregulation & Not tested & 56 \\
p-c-jun & Upregulation & Facilitation & 31 \\
TAK1 & Upregulation & Facilitation & 155 \\
TNF- $\alpha$ & Upregulation & Facilitation & 33 \\
TPA & Upregulation & & 86 \\
\hline ALXR & r & &
\end{tabular}

ALXR = lipoxin A4 receptor; bFGF = basic fibroblast factor; CCL2/MCP-1 = monocyte chemoattractant protein-1 (also called CCL2); $\mathrm{ERK}=$ extracellular signal-regulated kinase; GLAST = glutamate-aspartate transporter; GLT-1 = glutamate transporter-1; IL = interleukin; MMP-2 = matrix metalloproteinase-2; pJNK = phosphorylated c-Jun N-terminal kinase; TAK1 = transforming growth factor-activated kinase 1 ; TNF- $\alpha=$ tumor necrosis factor; TPA $=$ tissue type plasminogen activator. 

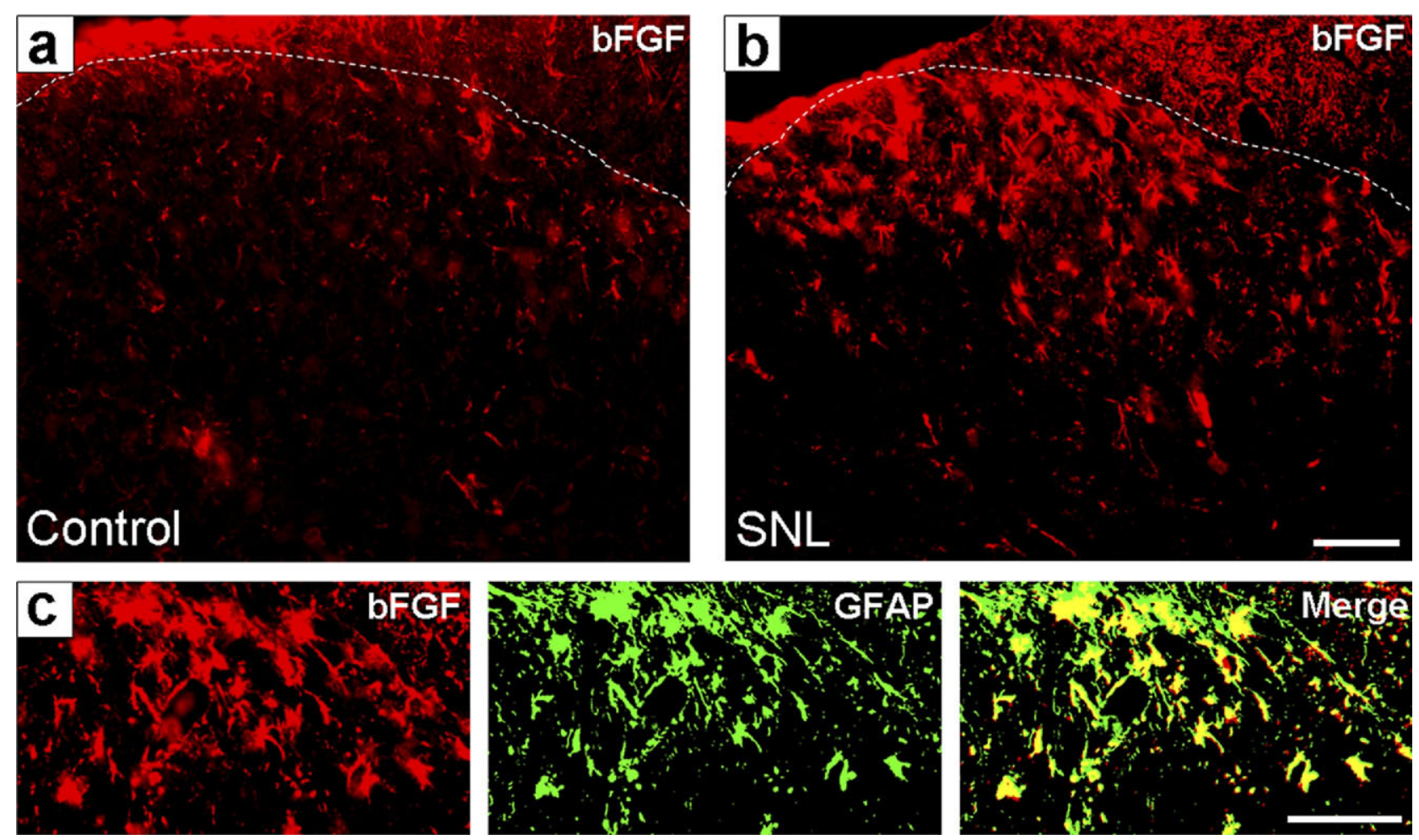

FIG. 2. Spinal nerve ligation (SNL) induces a marked basic fibroblast factor (bFGF) expression in spinal cord astrocytes. Double staining reveals a co-localization of bFGF with the astrocyte marker GFAP in the dorsal horn 3 weeks after nerve injury. (Scale, $50 \mu \mathrm{m}$.)

intrathecal administration of tPA inhibitor suppresses dorsal root ligation-induced mechanical allodynia. tPAplasmin system may alter the excitability of dorsal horn neurons and pain transmission through the activation of growth factors ${ }^{87,88}$ and modification of the NMDA receptors. ${ }^{89,90}$

Astrocytes are characterized by forming gap junctioncoupled networks, which could transmit $\mathrm{Ca}^{2+}$ signaling in the form of oscillations through the networks. ${ }^{91,92}$ The major structural components of gap junctions are connexins. In the mammalian nervous system, at least six connexins (Cx) (i.e., Cx26, Cx29, Cx30, Cx32, Cx36, and $\mathrm{Cx} 43$ ) have been identified. Among them, $\mathrm{Cx} 30$ and $\mathrm{Cx} 43$ are specifically expressed by astrocytes. ${ }^{93,94}$ Interestingly, the expression of $\mathrm{Cx} 43$ increases markedly in response to facial nerve lesion, ${ }^{95}$ spinal cord injury, ${ }^{96}$ and CFA-induced inflammation, ${ }^{32}$ indicating a role of $\mathrm{Cx}$ in chronic pain. Inhibition of gap junction function by carbenoxolone (i.e., a nonselective gap junction inhibitor) produces analgesia in different pain models. ${ }^{97-99}$ Particularly, intrathecal injection of carbenoxolone reduces sciatic nerve inflammation-induced mechanical allodynia in the contralateral paw, suggesting a role of astrocytes network and gap junction in the spread of pain beyond the injury site. ${ }^{98}$

In addition, astrocytes also express phosphorylated JNK and JNK1 (FIG. 1), ${ }^{31,56}$ phosphorylated extracellular signal-regulated kinase (ERK), ${ }^{53,100}$ endothelin re-
ceptor-B,${ }^{101}$ TNF- $\alpha,{ }^{33}$ basic fibroblast factor (bFGF) (FIG. 2), ${ }^{102,103}$ neurokinin-2 receptor, ${ }^{104}$ IL-18 receptor, ${ }^{47}$ IL- $1 \beta,{ }^{32,33,53,100}$ and monocyte chemoattractant protein-1 (MCP-1), ${ }^{52,105}$ in response to nerve injury or inflammation. Importantly, pharmacological inhibition of these signaling molecules via spinal cord administration has been shown to reduce chronic pain symptoms (Table 1).

\section{ASTROCYTES PRODUCE PRO-INFLAMMATORY CYTOKINES AND CHEMOKINES TO PROMOTE CHRONIC PAIN}

$\mathrm{IL}-1 \beta$ is a major pro-inflammatory cytokine and upregulated in the spinal cord under different chronic pain conditions. $^{35,62,106}$ Specifically, several studies have shown IL- $1 \beta$ upregulation in astrocytes after bone cancer, ${ }^{41}$ nerve injury, ${ }^{33}$ hind paw inflammation ${ }^{53,107}$ and masseter inflammation. ${ }^{32}$ IL- $1 \beta$ was also found in neurons in the spinal cord. ${ }^{108,109}$ Several lines of evidence support an important role of IL- $1 \beta$ for pain sensitization. Inhibition of spinal IL- $1 \beta$ signaling with intrathecal IL-1 receptor antagonist or neutralizing antibody has been shown to alleviate inflammatory, neuropathic, and cancer pain. ${ }^{32,33,62,106,107,110,111}$ Neuropathic pain is also markedly reduced in mouse strains with deletion of the IL-1 receptor type I or transgenic overexpression of IL-1 re- 
ceptor antagonist. ${ }^{112}$ Conversely, intrathecal injection of IL- $1 \beta$ is sufficient to elicit pain hypersensitivity. ${ }^{113-117}$

IL- $1 \beta$ released from astrocytes could directly modulate neuronal activity. Immunostaining shows that IL-1 receptor co-localizes with the NMDA receptor NR1 subunits in neurons of the spinal cord, ${ }^{107}$ trigeminal nucleus, ${ }^{32}$ and rostral ventromedial medulla. ${ }^{33}$ In primary cultured neurons, IL- $1 \beta$ regulates the phosphorylation of the NMDA receptor NR2B and NR1 subunit. ${ }^{32,118}$ IL$1 \beta$-mediated enhancement of NR1 subunit phosphorylation in the spinal cord may facilitate inflammatory pain and bone cancer pain. ${ }^{107,119}$ In particular, our ex vivo electrophysiological study using patch clamp recordings in lamina II neurons demonstrated that bath application of IL-1 $\beta$ onto isolated spinal cord slices can markedly enhance NMDA-induced current. ${ }^{106}$ Perfusion of spinal slices with IL-1 $\beta$ also increases the frequency and amplitude of spontaneous postsynaptic currents in dorsal horn neurons, indicating that IL- $1 \beta$ can directly enhance excitatory synaptic transmission. ${ }^{106}$ Although the frequency increase of spontaneous postsynaptic currents result from increased glutamate release from presynaptic terminals, the amplitude increase is caused by enhanced signaling of glutamate receptor ( $\alpha$-amino-3-hydroxy-5methyl-4-isoxazolepropionic acid [AMPA]-subtype) in postsynaptic sites. IL- $1 \beta$ also increases the excitability of nociceptors via IL-1R, which is expressed in small-size primary sensory neurons, ${ }^{120}$ leading to increased glutamate release in nociceptor central terminals in the spinal cord. Strikingly, IL-1 $\beta$ can further modulate inhibitory synaptic transmission in dorsal horn neurons. Bath application of IL- $1 \beta$ reduces the frequency and amplitude of spontaneous inhibitory postsynaptic currents and inhibits GABA- and glycine-induced currents in lamina II neurons, ${ }^{106}$ which will contribute to disinhibition (loss of inhibition), an important mechanism that is increasingly appreciated for the generation of neuropathic pain. ${ }^{121,122}$ Collectively, these studies suggest that IL- $1 \beta$ powerfully modulates synaptic transmission by: 1) enhancing excitatory synaptic transmission and 2) reducing inhibitory synaptic transmission. In addition, IL- $1 \beta$ also produces long-term neuronal plasticity in the pain circuit by inducing the phosphorylation of the transcription factor cAMP-response element binding protein ${ }^{9,106}$ and expression of cyclooxygenase- 2 in spinal cord neurons. ${ }^{123}$

IL- $1 \beta$ is synthesized as a precursor and requires a protease for its activation via cleavage to produce biological function. Notably, caspase- 1 is not the only enzyme for IL- $1 \beta$ cleavage. ${ }^{114}$ Metalloproteases have been implicated in the cleavage of extracellular matrix proteins, cytokines, and chemokines to control inflammation and tissue remodeling associated with various neurodegenerative diseases. ${ }^{124-127}$ Several studies showed that MMP-9 and MMP-2 are involved in IL- $1 \beta$ cleavage. ${ }^{114,125,128}$ Particularly, MMP-2 is persistently in- duced in astrocytes after spinal nerve ligation. ${ }^{114}$ Treatment of MMP-2 siRNA in the late-phase of nerve injury blocks IL- $1 \beta$ cleavage in the spinal cord and reduces mechanical allodynia. ${ }^{114}$ These data suggest that astrocyte-derived MMP-2 may maintain neuropathic pain by active cleavage of IL- $1 \beta$. MCP-1 (also called CCL2) is the chemokine that is highly produced by astrocytes.

MCP-1 expression is increased in spinal cord astrocytes after spinal nerve ligation ${ }^{52}$ and spinal cord contusion injuries. ${ }^{105}$ Several studies demonstrate that activated astrocytes in vitro also produce MCP-1..$^{52,129-132}$ The MCP-1 was found in astrocytes in the brain after demyelinating lesions, ${ }^{133,134}$ mechanical injury, ${ }^{135}$ entorhinodentate axon transaction, ${ }^{136}$ and focal cerebral ischemia. $^{137}$

CCR2, the major receptor of MCP-1, is expressed in dorsal root ganglion neurons and increased in these neurons after nerve injury. ${ }^{138}$ CCR2 is also constitutively expressed in spinal cord neurons, ${ }^{52,139}$ which is upregulated after nerve injury. ${ }^{52}$ Our recent study indicated a direct action of MCP-1 on spinal cord neurons. In isolated spinal cord slices, perfusion of MCP-1 immediately increases the frequencies of spontaneous postsynaptic currents and the amplitude in lamina II neurons of the dorsal horn. ${ }^{52}$ MCP-1 also rapidly $(<2 \mathrm{~min})$ enhances NMDA- and AMPA-induced inward currents, ${ }^{52}$ indicating a potentiation of glutamatergic synaptic transmission, which has been strongly implicated in central sensitization and hyperalgesia. ${ }^{9,122}$ In addition, Gosselin et al. ${ }^{139}$ demonstrated in neonatal cultures that MCP-1 inhibits GABA-induced currents in spinal neurons without affecting the electrical properties of these neurons. Thus, MCP-1 also modulates inhibitory synaptic transmission in spinal cord neurons.

In parallel with electrophysiological evidence, behavioral evidence shows that spinal injection of MCP-1 induces rapid heat hyperalgesia, starting at $15 \mathrm{~min}$, peaking at $30 \mathrm{~min}$, and recovering at $24 \mathrm{~h} .{ }^{52}$ Moreover, incubation of spinal cord slice with MCP-1 induces a rapid (within $5 \mathrm{~min}$ ) phosphorylation of the extracellular signal-regulated kinase in superficial dorsal horn neurons, ${ }^{52}$ which is regarded as a marker for spinal nociceptive neuron sensitization (central sensitization). ${ }^{140}$ Thus, the rapid phosphorylation of ERK in dorsal horn neurons by MCP-1 supports a direct action of MCP-1 on spinal cord neurons and its involvement in central sensitization. In neuropathic pain models, MCP-1 neutralizing antibody reduces mechanical allodynia induced by $\mathrm{SNL}^{52}$ or chronic constriction injury. ${ }^{141}$ Nerve injury-evoked mechanical allodynia is also reduced by CCR 2 antagonist or in mice lacking CCR2. ${ }^{142-145}$ Taken together, these studies demonstrate an important role of MCP-1/CCR2 in chronic pain via astrocyte-neuron interaction (FIG. 3). In addition to a direct action of neurons, astrocyte-produced MCP-1 may also act on microglia to induce proliferation 


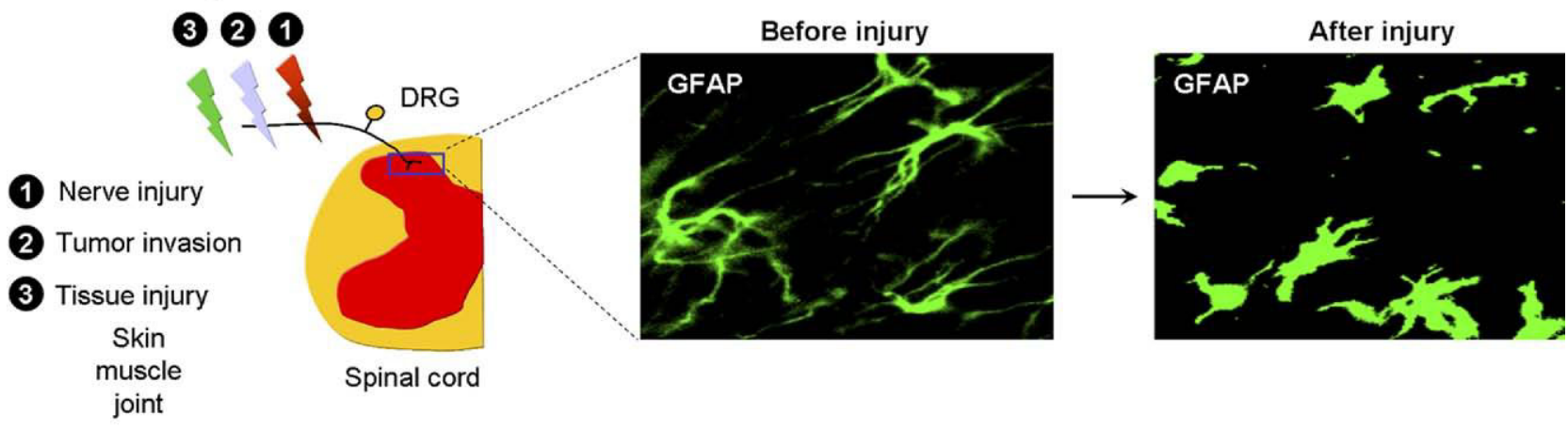

b

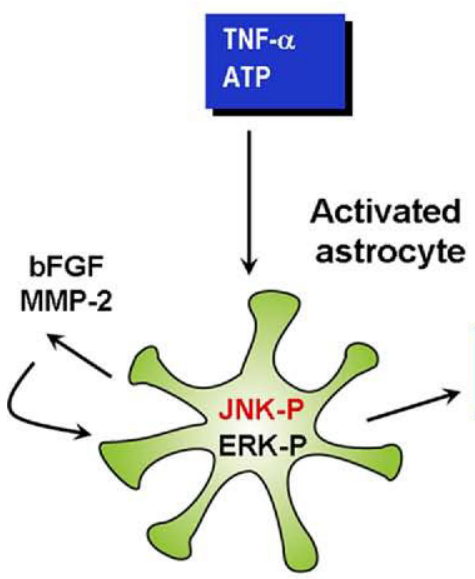

Primary afferents

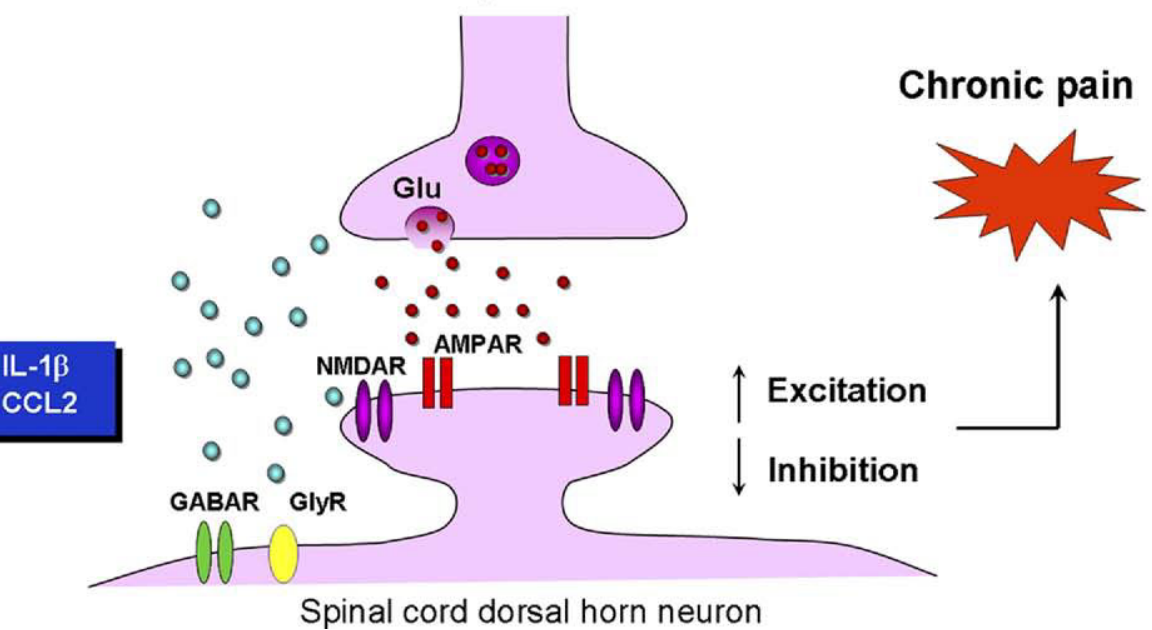

FIG. 3. Schematic showing how astrocytes in the spinal cord enhance synaptic transmission and promote chronic pain. (a) Peripheral injuries, such as nerve injury, tumor invasion (bone, nerve, and skin), and tissue injury (skin, muscle, joint) induce astrocyte reaction in the spinal cord. DRG = dorsal root ganglion. (b) Activated astrocytes show hyperphosphorylation of c-Jun N-terminal kinase (JNK) and extracellular signal-regulated kinase (ERK) (only in the late phase), which leads to the production and release of interleukin (IL)-1 $\beta$ and monocyte chemoattractant protein-1 (MCP-1). IL-1 $\beta$ and MCP-1 act on presynaptic sites in the primary afferents to enhance glutamate release. They also act on postsynaptic sites in nociceptive dorsal horn neurons to enhance excitatory synaptic transmission via NMDA and AMPA receptors, and suppress inhibitory synaptic transmission via GABA and glycine receptors. While tumor necrosis factor (TNF)- $\alpha$, mainly produced by microglia, induces transient activation of JNK, basic fibroblast factor, produced by astrocytes, elicits persistent activation of JNK. There is also a feedback loop between IL-1 $\beta$, phosphorylation of the extracellular signal-regulated kinase, and metalloproteases (MMP)-2. IL-1 $\beta$ activates ERK to releases MMP-2, which in turn induces cleavage and activation of IL-1 $\beta$. As a consequence of these signaling events in astrocytes, chronic pain is exaggerated and maintained. AMPAR $=\alpha$-amino-3-hydroxy-5methyl-4-isoxazolepropionic acid receptor; bFGF = basic fibroblast factor; GABAR = gamma-aminobutyric acid receptor; Glu = glutamate; GlyR = glycine receptor; NMDAR $=\mathrm{N}$-methyl-D-aspartate receptor.

and migration of microglia in the spinal cord, which can further enhance pain. ${ }^{143}$

\section{MAP KINASE SIGNALING IN ASTROCYTES ENHANCES CHRONIC PAIN}

Mounting evidence has demonstrated important roles of mitogen-activated protein kinases (MAPKs) (ERK, $\mathrm{p} 38$, and JNK) in chronic pain sensitization. ${ }^{146}$ Of interest, these MAPKs are differentially activated in spinal cord glial cells after nerve injury. Whereas p38 is persistently activated in microglia at all the times examined, ${ }^{31,147,148}$ ERK is only activated in microglia in the early phase (first several days) of nerve injury. ${ }^{100}$ In the late phase ( $>3$ weeks) of nerve injury, phosphorylation of ERK is induced in spinal astrocytes. ${ }^{42,100}$ Spinal inhibition of this late-phase activation of ERK by intrathecal administration of an MAP kinase and ERK kinase inhibitor reverses mechanical allodynia, implicating a role of astrocytic ERK in the maintenance of neuropathic pain. ${ }^{100}$ Intraplantar injection of CFA also induces phosphorylation of ERK in spinal cord astrocytes in the latephase of this inflammatory pain condition. ${ }^{149}$

We will focus our discussion on JNK, also called stress-activated protein kinase, which is well known for its role in regulating apoptosis and neurodegeneration, ${ }^{140}$ but JNK activation in spinal astrocytes after peripheral nerve injury is not associated with apoptosis in astro- 
cytes. ${ }^{31}$ Rather, JNK activation in astrocytes regulates the expression and release of chemokines. ${ }^{52}$ SNL induces a persistent ( $>3$ weeks) increase of phosphorylated JNK (pJNK) in the spinal cord, particularly in reactive astrocytes. ${ }^{31}$ Increase in pJNK was also found in spinal astrocytes in other neuropathic conditions, such as partial sciatic nerve injury ${ }^{42}$ and amyotrophic lateral sclerosis. ${ }^{150}$ pJNK is further induced in spinal cord astrocytes in inflammatory pain conditions after intraplantar injection of carrageenan ${ }^{55}$ and CFA. ${ }^{56}$ In particular, CFA elicits a bilateral phosphorylation of JNK, starting at 6 hours and maintaining after 2 weeks. ${ }^{56}$ Despite there are three isoforms of JNK (JNK1, JNK2, and JNK3), $\mathrm{JNK} 1$ is the isoform that is expressed in spinal astrocytes and hyperphosphorylated after SNL and CFA injection. ${ }^{31,56}$ In parallel, inflammatory pain is reduced in mice lacking JNK1, but not JNK2. ${ }^{56}$

The role of astrocyte JNK in pain control has been also evaluated by intrathecal injection of the JNK inhibitor SP600125. Administration of SP600125, either before or after nerve injury, can both attenuate neuropathic pain after SNL. ${ }^{31,151}$ SP600125 also suppresses neuropathic pain in a diabetes model of neuropathic pain. ${ }^{152}$ The peptide inhibitor D-JNKI-1 is a more potent and selective inhibitor of JNK. A single bolus injection of D-JNKI-1 can block SNL-induced mechanical allodynia for more than 6 hours. ${ }^{31}$

How does JNK signaling in astrocytes control chronic pain? JNK activation in astrocytes results in the production of various inflammatory mediators. In cultured astrocytes there is a JNK-dependent expression of cyclooxygenase- 2 and inducible nitric oxide synthase, as well as the release of nitric oxide, prostaglandin E2 and IL$6 .{ }^{153}$ Notably, stimulation of astrocytes with TNF- $\alpha$ not only activates JNK, but also induces a marked upregulation of several chemokines, such as MCP-1, keratinocyte-derived chemokine, and IFN- $\gamma$-inducible protein $10{ }^{52}$ Strikingly, TNF- $\alpha$ induces a substantial increase ( $>100$-fold), both in the expression and release of MCP-1 in astrocyte cultures; this increase is completely blocked by JNK inhibition. ${ }^{52}$ JNK activation in astrocytes also leads to the production of MCP-1 in vivo. ${ }^{52}$ Thus, JNK activation in astrocytes can enhance pain via producing chemokines such as MCP-1, which is known to increase the sensitivity of dorsal horn neurons. ${ }^{154}$

JNK is activated by the transforming growth factoractivated kinase 1, a member of the MAPK kinase family. Interestingly, peripheral nerve injury induces transforming growth factor-activated kinase 1 upregulation in hyperactive astrocytes in the spinal cord. ${ }^{155}$ Intrathecal administration of transforming growth factor-activated kinase 1 anti-sense oligodeoxynucleotides, either before and after nerve injury, can reduce nerve injury-induced mechanical allodynia. ${ }^{155}$
bFGF is a well-known activator of astrocytes and induces mitosis, growth, differentiation, and gliosis of astrocytes. ${ }^{156,157}$ Spinal nerve ligation induces a substantial increase of bFGF in reactive astrocytes in the late phase (3 weeks after injury, FIG. 2). Intrathecal infusion of bFGF induces persistent JNK phosphorylation and GFAP expression in the spinal cord, which is associated with the development of mechanical allodynia. ${ }^{22}$ Conversely, intrathecal injection of a bFGF neutralizing antibody can reverse nerve injury-induced mechanical allodynia. ${ }^{102}$ Compared to a transient JNK activation by TNF- $\alpha$, bFGF induces a sustained activation of JNK in astrocyte cultures. $^{22,52}$ Therefore, $\mathrm{bFGF}$, produced in astrocytes in the late-phase of injury, may maintain chronic pain via sustained JNK activation in astrocytes.

\section{CONCLUSIONS AND CLINICAL IMPLICATIONS}

In summary, we have reviewed behavioral, histochemical, and electrophysiological evidence to support a rising role of astrocytes in chronic pain sensitization. We also demonstrate how astrocytes promote chronic pain via neuronal-glial interactions (FIG. 3). After peripheral nerve injury or tissue damage in the skin, muscle, or joint (e.g., arthritis), astrocytes are activated in the spinal cord in response to neurotransmitters/neuromodulators (e.g., ATP, glutamate, neuropeptides), and inflammatory mediators (e.g., TNF- $\alpha$ ) released after injuries. Astrocyte activation may manifest as the activation of several intracellular signaling pathways, such as the JNK and ERK pathways or/and upregulation of GFAP and astrogliosis/ hypertrophy (FIG. 3a). Activation of the JNK or/and ERK results in the production of pro-inflammatory cytokines and chemokines (e.g., IL-1 $\beta$ and MCP-1). These mediators can act at both presynaptic sites on primary afferents and postsynaptic sites on dorsal horn neurons to increase excitation and decrease inhibition of spinal cord nociceptive neurons, leading to enhanced pain states (FIG. 3b).

Given the important role of astrocytes in chronic pain facilitation, targeting astrocytes could reveal novel therapies for the management of chronic pain. However, caution must be taken when we consider strategies to target astrocytes, because astrocytes play an essential supportive and protective role in the CNS. ${ }^{158}$ Inhibition of reactive astrocytes with the toxin fluorocitrate has been shown to retard neurovascular remodeling and recovery after focal cerebral ischemia. ${ }^{159}$ Thus, it is important to target specific signaling events in astroctyes without disrupting the overall well being of astrocytes. As discussed in Table 1, all the signaling molecules that are induced in astrocytes under chronic pain conditions and that contribute to pain behaviors can be potentially targeted. In particular, JNK inhibitor not only exhibits 
anti-allodynic action, but it also has a neuroprotecitve role. ${ }^{160}$ JNK inhibitor further reduces tumor growth ${ }^{36}$ and insulin resistance ${ }^{161,162}$; therefore, JNK inhibitor should be beneficial in pain conditions associated with cancer and diabetic neuropathy.

Finally, it is worth noting that all the evidence we present is from animal studies. Indeed, astrocytes from humans are quite different. ${ }^{163}$ The human brain seems to contain subtypes of GFAP-positive astrocytes that are not represented in rodents. Strikingly, in the human cortex, astrocytes are $>2$-fold larger in diameter and extend 10 -fold more GFAP-positive primary processes than their rodent counterparts. The domain of a single human astrocyte has been estimated to contain as many as 2 million synapses. ${ }^{164}$ Hence, it is reasonable to postulate human astrocytes may play a more important role in chronic pain control than rodent astrocytes.

Acknowledgments: This work was supported by the National Institutes of Health R01 Grant No. NS54932, Grant No. NS67686, and Grant No. DE17794.

\section{REFERENCES}

1. Julius D, Basbaum AI. Molecular mechanisms of nociception. Nature 2001;413:203-210.

2. Lundeberg T, Ekholm J. Pain-from periphery to brain. Disabil Rehabil 2002;24:402-406.

3. Millan MJ. Descending control of pain. Prog Neurobiol 2002;66: 355-474.

4. Woolf CJ, Mannion RJ. Neuropathic pain: aetiology, symptoms, mechanisms, and management. Lancet 1999;353:1959-1964.

5. Dubner R, Ruda MA. Activity-dependent neuronal plasticity following tissue injury and inflammation. Trends Neurosci 1992;15: 96-103.

6. Mantyh PW, Clohisy DR, Koltzenburg M, Hunt SP. Molecular mechanisms of cancer pain. Nat Rev Cancer 2002;2:201-209.

7. Willis CL, Davis TP. Chronic inflammatory pain and the neurovascular unit: a central role for glia in maintaining BBB integrity? Curr Pharm Des 2008;14:1625-1643.

8. Costigan M, Scholz J, Woolf CJ. Neuropathic pain: a maladaptive response of the nervous system to damage. Annu Rev Neurosci 2009;32:1-32.

9. Ji RR, Kohno T, Moore KA, Woolf CJ. Central sensitization and LTP: do pain and memory share similar mechanisms? Trends Neurosci 2003;26:696-705.

10. Basbaum AI, Bautista DM, Scherrer G, Julius D. Cellular and molecular mechanisms of pain. Cell 2009;139:267-284.

11. Dworkin RH, Backonja M, Rowbotham MC, et al. Advances in neuropathic pain: diagnosis, mechanisms, and treatment recommendations. Arch Neurol 2003;60:1524-1534.

12. Ho KY, Siau C. Chronic pain management: therapy, drugs and needles. Ann Acad Med Singapore 2009;38:929-930.

13. Moalem G, Tracey DJ. Immune and inflammatory mechanisms in neuropathic pain. Brain Res Rev 2006;51:240-264.

14. Aldskogius H, Kozlova EN. Central neuron-glial and glial-glial interactions following axon injury. Prog Neurobiol 1998;55:1-26.

15. Nimmerjahn A, Kirchhoff F, Helmchen F. Resting microglial cells are highly dynamic surveillants of brain parenchyma in vivo. Science 2005;308:1314-1318.

16. Rossi DJ, Brady JD, Mohr C. Astrocyte metabolism and signaling during brain ischemia. Nat Neurosci 2007;10:1377-1386.

17. Hanisch UK, Kettenmann H. Microglia: active sensor and versatile effector cells in the normal and pathologic brain. Nat Neurosci 2007;10:1387-1394.

18. Scholz J, Woolf CJ. The neuropathic pain triad: neurons, immune cells and glia. Nat Neurosci 2007;10:1361-1368.
19. McMahon SB, Malcangio M. Current challenges in glia-pain biology. Neuron 2009;64:46-54.

20. Ren K, Dubner R. Neuron-glia crosstalk gets serious: role in pain hypersensitivity. Curr Opin Anaesthesiol 2008;21:570-579.

21. Hansson E. Could chronic pain and spread of pain sensation be induced and maintained by glial activation? Acta Physiol (Oxf) 2006;187:321-327.

22. Ji RR, Kawasaki Y, Zhuang ZY, Wen YR, Decosterd I. Possible role of spinal astrocytes in maintaining chronic pain sensitization: review of current evidence with focus on $\mathrm{bFGF/JNK}$ pathway. Neuron Glia Biol 2006;2:259-269.

23. Suter MR, Wen YR, Decosterd I, Ji RR. Do glial cells control pain? Neuron Glia Biol 2007;3:255-268.

24. Watkins LR, Hutchinson MR, Ledeboer A, et al. Norman Cousins Lecture. Glia as the "bad guys": implications for improving clinical pain control and the clinical utility of opioids. Brain Behav Immun 2007;21:131-146.

25. Romero-Sandoval EA, Horvath RJ, DeLeo JA. Neuroimmune interactions and pain: focus on glial-modulating targets. Curr Opin Investig Drugs 2008;9:726-734.

26. Hald A. Spinal astrogliosis in pain models: cause and effects. Cell Mol Neurobiol 2009;29:609-619.

27. Milligan ED, Watkins LR. Pathological and protective roles of glia in chronic pain. Nat Rev Neurosci 2009;10:23-36.

28. Halassa MM, Fellin T, Takano H, Dong JH, Haydon PG. Synaptic islands defined by the territory of a single astrocyte. J Neurosci 2007;27:6473-6477.

29. Garrison CJ, Dougherty PM, Kajander KC, Carlton SM. Staining of glial fibrillary acidic protein (GFAP) in lumbar spinal cord increases following a sciatic nerve constriction injury. Brain Res 1991;565:1-7.

30. Colburn RW, Rickman AJ, DeLeo JA. The effect of site and type of nerve injury on spinal glial activation and neuropathic pain behavior. Exp Neurol 1999;157:289-304.

31. Zhuang ZY, Wen YR, Zhang DR, et al. A peptide c-Jun Nterminal kinase (JNK) inhibitor blocks mechanical allodynia after spinal nerve ligation: respective roles of JNK activation in primary sensory neurons and spinal astrocytes for neuropathic pain development and maintenance. J Neurosci 2006;26:3551-3560.

32. Guo W, Wang H, Watanabe M, et al. Glial-cytokine-neuronal interactions underlying the mechanisms of persistent pain. J Neurosci 2007;27:6006-6018.

33. Wei F, Guo W, Zou S, Ren K, Dubner R. Supraspinal glialneuronal interactions contribute to descending pain facilitation. J Neurosci 2008;28:10482-10495.

34. Raghavendra V, Tanga FY, DeLeo JA. Complete Freunds adjuvant-induced peripheral inflammation evokes glial activation and proinflammatory cytokine expression in the CNS. Eur J Neurosci 2004;20:467-473.

35. Sweitzer SM, Colburn RW, Rutkowski M, DeLeo JA. Acute peripheral inflammation induces moderate glial activation and spinal IL-1beta expression that correlates with pain behavior in the rat. Brain Res 1999;829:209-221.

36. Gao YJ, Cheng JK, Zeng Q, et al. Selective inhibition of JNK with a peptide inhibitor attenuates pain hypersensitivity and tumor growth in a mouse skin cancer pain model. Exp Neurol 2009;219:146-55.

37. Fujita M, Andoh T, Ohashi K, et al. Roles of kinin B1 and B2 receptors in skin cancer pain produced by orthotopic melanoma inoculation in mice. Eur J Pain 2010;14:588-594.

38. Zhang HW, Iida Y, Andoh T, et al. Mechanical hypersensitivity and alterations in cutaneous nerve fibers in a mouse model of skin cancer pain. J Pharmacol Sci 2003;91:167-170.

39. Schwei MJ, Honore P, Rogers SD, et al. Neurochemical and cellular reorganization of the spinal cord in a murine model of bone cancer pain. J Neurosci 1999;19:10886-10897.

40. Hald A, Nedergaard S, Hansen RR, Ding M, Heegaard AM. Differential activation of spinal cord glial cells in murine models of neuropathic and cancer pain. Eur J Pain 2009;13:138-145.

41. Zhang RX, Liu B, Wang L, et al. Spinal glial activation in a new rat model of bone cancer pain produced by prostate cancer cell inoculation of the tibia. Pain 2005;118:125-136. 
42. Ma W, Quirion R. Partial sciatic nerve ligation induces increase in the phosphorylation of extracellular signal-regulated kinase (ERK) and c-Jun N-terminal kinase (JNK) in astrocytes in the lumbar spinal dorsal horn and the gracile nucleus. Pain 2002;99: 175-184.

43. Zhang J, De Koninck Y. Spatial and temporal relationship between monocyte chemoattractant protein-1 expression and spinal glial activation following peripheral nerve injury. J Neurochem 2006;97:772-783.

44. Tanga FY, Raghavendra V, DeLeo JA. Quantitative real-time RT-PCR assessment of spinal microglial and astrocytic activation markers in a rat model of neuropathic pain. Neurochem Int 2004; 45:397-407.

45. Cavaliere C, Cirillo G, Rosaria Bianco M, et al. Gliosis alters expression and uptake of spinal glial amino acid transporters in a mouse neuropathic pain model. Neuron Glia Biol 2007;3:141153.

46. Svensson M, Eriksson NP, Aldskogius H. Evidence for activation of astrocytes via reactive microglial cells following hypoglossal nerve transection. J Neurosci Res 1993;35:373-381.

47. Miyoshi K, Obata K, Kondo T, Okamura H, Noguchi K. Interleukin-18-mediated microglia/astrocyte interaction in the spinal cord enhances neuropathic pain processing after nerve injury. J Neurosci 2008;28:12775-12787.

48. Garrison CJ, Dougherty PM, Carlton SM. GFAP expression in lumbar spinal cord of naive and neuropathic rats treated with MK-801. Exp Neurol 1994;129:237-243.

49. Chen JJ, Lue JH, Lin LH, et al. Effects of pre-emptive drug treatment on astrocyte activation in the cuneate nucleus following rat median nerve injury. Pain 2010;148:158-166.

50. Colburn RW, DeLeo JA, Rickman AJ, et al. Dissociation of microglial activation and neuropathic pain behaviors following peripheral nerve injury in the rat. J Neuroimmunol 1997;79: 163-175.

51. Kim DS, Figueroa KW, Li KW, et al. Profiling of dynamically changed gene expression in dorsal root ganglia post peripheral nerve injury and a critical role of injury-induced glial fibrillary acidic protein in maintenance of pain behaviors [corrected]. Pain 2009; $143: 114-122$.

52. Gao YJ, Zhang L, Samad OA, et al. JNK-induced MCP-1 production in spinal cord astrocytes contributes to central sensitization and neuropathic pain. J Neurosci 2009;29:4096-4108.

53. Weyerbacher AR, Xu Q, Tamasdan C, Shin SJ, Inturrisi CE. N-Methyl-D-aspartate receptor (NMDAR) independent maintenance of inflammatory pain. Pain 2010;148:237-246.

54. Svensson CI, Brodin E. Spinal astrocytes in pain processing: non-neuronal cells as therapeutic targets. Mol Interv 2010;10: 25-38.

55. Svensson CI, Zattoni M, Serhan CN. Lipoxins and aspirin-triggered lipoxin inhibit inflammatory pain processing. J Exp Med 2007;204:245-252.

56. Gao YJ, Xu ZZ, Liu YC, et al. The c-Jun N-terminal kinase 1 (JNK1) in spinal astrocytes is required for the maintenance of bilateral mechanical allodynia under a persistent inflammatory pain condition. Pain 2010;148:309-319.

57. Hofstetter CP, Holmstrom NA, Lilja JA, et al. Allodynia limits the usefulness of intraspinal neural stem cell grafts; directed differentiation improves outcome. Nat Neurosci 2005;8:346-353.

58. Davies JE, Proschel C, Zhang N, et al. Transplanted astrocytes derived from BMP- or CNTF-treated glial-restricted precursors have opposite effects on recovery and allodynia after spinal cord injury. J Biol 2008;7:24.

59. Gao YJ, Zhang L, Ji RR. Spinal injection of TNF- $\alpha$-activated astrocytes produces persistent pain symptom-mechanical allodynia by releasing monocyte chemoattractant protein-1. Glia 2010 (in press).

60. Meller ST, Dykstra C, Grzybycki D, Murphy S, Gebhart GF. The possible role of glia in nociceptive processing and hyperalgesia in the spinal cord of the rat. Neuropharmacology 1994;33:14711478.

61. Watkins LR, Martin D, Ulrich P, Tracey KJ, Maier SF. Evidence for the involvement of spinal cord glia in subcutaneous formalin induced hyperalgesia in the rat. Pain 1997;71:225-235.
62. Milligan ED, Twining C, Chacur M, et al. Spinal glia and proinflammatory cytokines mediate mirror-image neuropathic pain in rats. J Neurosci 2003;23:1026-1040.

63. Obata H, Eisenach JC, Hussain H, Bynum T, Vincler M. Spinal glial activation contributes to postoperative mechanical hypersensitivity in the rat. J Pain 2006;7:816-822.

64. Clark AK, Gentry C, Bradbury EJ, McMahon SB, Malcangio M. Role of spinal microglia in rat models of peripheral nerve injury and inflammation. Eur J Pain 2007;11:223-230.

65. Okada-Ogawa A, Suzuki I, Sessle BJ, et al. Astroglia in medullary dorsal horn (trigeminal spinal subnucleus caudalis) are involved in trigeminal neuropathic pain mechanisms. J Neurosci 2009;29:11161-11171.

66. Ledeboer A, Mahoney JH, Milligan ED, et al. Spinal cord glia and interleukin-1 do not appear to mediate persistent allodynia induced by intramuscular acidic saline in rats. J Pain 2006;7: 757-767.

67. Huck S, Grass F, Hortnagl H. The glutamate analogue alphaaminoadipic acid is taken up by astrocytes before exerting its gliotoxic effect in vitro. J Neurosci 1984;4:2650-2657.

68. Khurgel M, Koo AC, Ivy GO. Selective ablation of astrocytes by intracerebral injections of alpha-aminoadipate. Glia 1996;16: 351-358.

69. Rodriguez MJ, Martinez-Sanchez M, Bernal F, Mahy N. Heterogeneity between hippocampal and septal astroglia as a contributing factor to differential in vivo AMPA excitotoxicity. J Neurosci Res 2004;77:344-353.

70. Wang W, Wang W, Mei X, et al. Crosstalk between spinal astrocytes and neurons in nerve injury-induced neuropathic pain. PLoS One 2009;4:e6973.

71. Beart PM, O'Shea RD. Transporters for L-glutamate: an update on their molecular pharmacology and pathological involvement. Br J Pharmacol 2007;150:5-17.

72. Huang YH, Bergles DE. Glutamate transporters bring competition to the synapse. Curr Opin Neurobiol 2004;14:346-352.

73. Tawfik VL, Lacroix-Fralish ML, Bercury KK, et al. Induction of astrocyte differentiation by propentofylline increases glutamate transporter expression in vitro: heterogeneity of the quiescent phenotype. Glia 2006;54:193-203.

74. Rothstein JD, Dykes-Hoberg M, Pardo CA, et al. Knockout of glutamate transporters reveals a major role for astroglial transport in excitotoxicity and clearance of glutamate. Neuron 1996;16: 675-686.

75. Tanaka K, Watase K, Manabe T, et al. Epilepsy and exacerbation of brain injury in mice lacking the glutamate transporter GLT-1. Science 1997;276:1699-702.

76. Katagiri H, Tanaka K, Manabe T. Requirement of appropriate glutamate concentrations in the synaptic cleft for hippocampal LTP induction. Eur J Neurosci 2001;14:547-553.

77. Levenson J, Weeber E, Selcher JC, et al. Long-term potentiation and contextual fear conditioning increase neuronal glutamate uptake. Nat Neurosci 2002;5:155-161.

78. Sung B, Lim G, Mao J. Altered expression and uptake activity of spinal glutamate transporters after nerve injury contribute to the pathogenesis of neuropathic pain in rats. J Neurosci 2003;23: 2899-2910.

79. Wang W, Wang W, Wang Y, et al. Temporal changes of astrocyte activation and glutamate transporter-1 expression in the spinal cord after spinal nerve ligation-induced neuropathic pain. Anat Rec (Hoboken) 2008;291:513-518.

80. Xin WJ, Weng HR, Dougherty PM. Plasticity in expression of the glutamate transporters GLT-1 and GLAST in spinal dorsal horn glial cells following partial sciatic nerve ligation. Mol Pain 2009;5:15.

81. Tawfik VL, Regan MR, Haenggeli C, et al. Propentofyllineinduced astrocyte modulation leads to alterations in glial glutamate promoter activation following spinal nerve transection. Neuroscience 2008;152:1086-1092.

82. Liaw WJ, Stephens RL, Jr., Binns BC, et al. Spinal glutamate uptake is critical for maintaining normal sensory transmission in rat spinal cord. Pain 2005;115:60-70.

83. Weng HR, Chen JH, Cata JP. Inhibition of glutamate uptake in the spinal cord induces hyperalgesia and increased responses of 
spinal dorsal horn neurons to peripheral afferent stimulation. Neuroscience 2006;138:1351-1360.

84. Maeda S, Kawamoto A, Yatani Y, et al. Gene transfer of GLT-1, a glial glutamate transporter, into the spinal cord by recombinant adenovirus attenuates inflammatory and neuropathic pain in rats. Mol Pain 2008;4:65.

85. Chiang CY, Wang J, Xie YF, et al. Astroglial glutamateglutamine shuttle is involved in central sensitization of nociceptive neurons in rat medullary dorsal horn. J Neurosci 2007; 27:9068-76.

86. Kozai T, Yamanaka H, Dai Y, et al. Tissue type plasminogen activator induced in rat dorsal horn astrocytes contributes to mechanical hypersensitivity following dorsal root injury. Glia 2007;55:595-603.

87. Bruno MA, Cuello AC. Activity-dependent release of precursor nerve growth factor, conversion to mature nerve growth factor, and its degradation by a protease cascade. Proc Natl Acad Sci U S A 2006;103:6735-6740.

88. Pang PT, Teng HK, Zaitsev E, et al. Cleavage of proBDNF by tPA/plasmin is essential for long-term hippocampal plasticity. Science 2004;306:487-491.

89. Hoffman KB, Martinez J, Lynch G. Proteolysis of cell adhesion molecules by serine proteases: a role in long term potentiation? Brain Res 1998;811:29-33.

90. Qian Z, Gilbert ME, Colicos MA, Kandel ER, Kuhl D. Tissueplasminogen activator is induced as an immediate-early gene during seizure, kindling and long-term potentiation. Nature 1993; 361:453-457.

91. Blomstrand F, Khatibi S, Muyderman H, et al. 5-Hydroxytryptamine and glutamate modulate velocity and extent of intercellular calcium signalling in hippocampal astroglial cells in primary cultures. Neuroscience 1999;88:1241-1253.

92. Haydon PG. GLIA: listening and talking to the synapse. Nat Rev Neurosci 2001;2:185-193.

93. Giaume C, McCarthy KD. Control of gap-junctional communication in astrocytic networks. Trends Neurosci 1996;19:319-325.

94. Nagy JI, Dudek FE, Rash JE. Update on connexins and gap junctions in neurons and glia in the mammalian nervous system. Brain Res Brain Res Rev 2004;47:191-215.

95. Rohlmann A, Laskawi R, Hofer A, et al. Facial nerve lesions lead to increased immunostaining of the astrocytic gap junction protein (connexin 43) in the corresponding facial nucleus of rats. Neurosci Lett 1993;154:206-208.

96. Lee IH, Lindqvist E, Kiehn O, Widenfalk J, Olson L. Glial and neuronal connexin expression patterns in the rat spinal cord during development and following injury. J Comp Neurol 2005;489: $1-10$.

97. Qin M, Wang JJ, Cao R, et al. The lumbar spinal cord glial cells actively modulate subcutaneous formalin induced hyperalgesia in the rat. Neurosci Res 2006;55:442-450.

98. Spataro LE, Sloane EM, Milligan ED, et al. Spinal gap junctions: potential involvement in pain facilitation. J Pain 2004;5:392-405.

99. Lan L, Yuan H, Duan L, et al. Blocking the glial function suppresses subcutaneous formalin-induced nociceptive behavior in he rat. Neurosci Res 2007;57:112-129.

100. Zhuang ZY, Gerner P, Woolf CJ, Ji RR. ERK is sequentially activated in neurons, microglia, and astrocytes by spinal nerve ligation and contributes to mechanical allodynia in this neuropathic pain model. Pain 2005;114:149-159.

101. Peters CM, Rogers SD, Pomonis JD, et al. Endothelin receptor expression in the normal and injured spinal cord: potential involvement in injury-induced ischemia and gliosis. Exp Neurol 2003;180:1-13.

102. Madiai F, Goettl VM, Hussain SR, et al. Anti-fibroblast growth factor-2 antibodies attenuate mechanical allodynia in a rat model of neuropathic pain. J Mol Neurosci 2005;27:315-324.

103. Madiai F, Hussain SR, Goettl VM, et al. Upregulation of FGF-2 in reactive spinal cord astrocytes following unilateral lumbar spinal nerve ligation. Exp Brain Res 2003;148:366-376.

104. Garry EM, Delaney A, Blackburn-Munro G, et al. Activation of p38 and p42/44 MAP kinase in neuropathic pain: involvement of VPAC2 and NK2 receptors and mediation by spinal glia. Mol Cell Neurosci 2005;30:523-537.
105. Knerlich-Lukoschus F, Juraschek M, Blomer U, et al. Forcedependent development of neuropathic central pain and timerelated CCL2/CCR2 expression after graded spinal cord contusion injuries of the rat. J Neurotrauma 2008;25:427-448.

106. Kawasaki Y, Zhang L, Cheng JK, Ji RR. Cytokine mechanisms of central sensitization: distinct and overlapping role of interleukin1 beta, interleukin-6, and tumor necrosis factor-alpha in regulating synaptic and neuronal activity in the superficial spinal cord. J Neurosci 2008;28:5189-5194.

107. Zhang RX, Li A, Liu B, et al. IL-1ra alleviates inflammatory hyperalgesia through preventing phosphorylation of NMDA receptor NR-1 subunit in rats. Pain 2008;135:232-239.

108. DeLeo JA, Colburn RW, Rickman AJ. Cytokine and growth factor immunohistochemical spinal profiles in two animal models of mononeuropathy. Brain Res 1997;759:50-57.

109. Fu D, Guo Q, Ai Y, et al. Glial activation and segmental upregulation of interleukin-1beta (IL-1beta) in the rat spinal cord after surgical incision. Neurochem Res 2006;31:333-340.

110. Milligan ED, O'Connor KA, Nguyen KT, et al. Intrathecal HIV-1 envelope glycoprotein gp120 induces enhanced pain states mediated by spinal cord proinflammatory cytokines. J Neurosci 2001; 21:2808-2819.

111. Sweitzer S, Martin D, DeLeo JA. Intrathecal interleukin-1 receptor antagonist in combination with soluble tumor necrosis factor receptor exhibits an anti-allodynic action in a rat model of neuropathic pain. Neuroscience 2001;103:529-539.

112. Wolf G, Gabay E, Tal M, Yirmiya R, Shavit Y. Genetic impairment of interleukin-1 signaling attenuates neuropathic pain, autotomy, and spontaneous ectopic neuronal activity, following nerve injury in mice. Pain 2006;120:315-324.

113. Ji GC, Zhang YQ, Ma F, Wu GC. Increase of nociceptive threshold induced by intrathecal injection of interleukin-1beta in normal and carrageenan inflammatory rat. Cytokine 2002;19:31-36.

114. Kawasaki Y, Xu ZZ, Wang X, et al. Distinct roles of matrix metalloproteases in the early- and late-phase development of neuropathic pain. Nat Med 2008;14:331-336.

115. Tadano T, Namioka M, Nakagawasai O, et al. Induction of nociceptive responses by intrathecal injection of interleukin-1 in mice. Life Sci 1999;65:255-261.

116. Sung CS, Wen ZH, Chang WK, et al. Intrathecal interleukin1beta administration induces thermal hyperalgesia by activating inducible nitric oxide synthase expression in the rat spinal cord. Brain Res 2004;1015:145-153.

117. Reeve AJ, Patel S, Fox A, Walker K, Urban L. Intrathecally administered endotoxin or cytokines produce allodynia, hyperalgesia and changes in spinal cord neuronal responses to nociceptive stimuli in the rat. Eur J Pain 2000;4:247-257.

118. Tsakiri N, Kimber I, Rothwell NJ, Pinteaux E. Interleukin-1induced interleukin-6 synthesis is mediated by the neutral sphingomyelinase/Src kinase pathway in neurones. Br J Pharmacol 2008;153:775-783.

119. Zhang RX, Liu B, Li A, et al. Interleukin 1beta facilitates bone cancer pain in rats by enhancing NMDA receptor NR-1 subunit phosphorylation. Neuroscience 2008;154:1533-1558.

120. Binshtok AM, Wang H, Zimmermann K, et al. Nociceptors are interleukin-1beta sensors. J Neurosci 2008;28:14062-14073.

121. Coull JA, Beggs S, Boudreau D, et al. BDNF from microglia causes the shift in neuronal anion gradient underlying neuropathic pain. Nature 2005;438:1017-1021.

122. Woolf CJ, Salter MW. Neuronal plasticity: increasing the gain in pain. Science 2000;288:1765-1769.

123. Samad TA, Moore KA, Sapirstein A, et al. Interleukin-1betamediated induction of Cox-2 in the CNS contributes to inflammatory pain hypersensitivity. Nature 2001;410:471-475.

124. Rosenberg GA. Matrix metalloproteinases in neuroinflammation. Glia 2002;39:279-291.

125. Parks WC, Wilson CL, Lopez-Boado YS. Matrix metalloproteinases as modulators of inflammation and innate immunity. Nat Rev Immunol 2004;4:617-629.

126. Yong VW. Metalloproteinases: mediators of pathology and regeneration in the CNS. Nat Rev Neurosci 2005;6:931-944.

127. Manicone AM, McGuire JK. Matrix metalloproteinases as modulators of inflammation. Semin Cell Dev Biol 2008;19:34-41. 
128. Schonbeck U, Mach F, Libby P. Generation of biologically active IL-1 beta by matrix metalloproteinases: a novel caspase-1independent pathway of IL-1 beta processing. J Immunol 1998; 161:3340-3346

129. Croitoru-Lamoury J, Guillemin GJ, Boussin FD, et al. Expression of chemokines and their receptors in human and simian astrocytes: evidence for a central role of TNF alpha and IFN gamma in CXCR4 and CCR5 modulation. Glia 2003;41:354-370.

130. Meeuwsen S, Persoon-Deen C, Bsibsi M, Ravid R, van Noort JM. Cytokine, chemokine and growth factor gene profiling of cultured human astrocytes after exposure to proinflammatory stimuli. Glia 2003;43:243-253.

131. El-Hage N, Gurwell JA, Singh IN, et al. Synergistic increases in intracellular $\mathrm{Ca} 2+$, and the release of MCP-1, RANTES, and IL- 6 by astrocytes treated with opiates and HIV-1 Tat. Glia 2005;50:91-106.

132. Mojsilovic-Petrovic J, Callaghan D, Cui H, et al. Hypoxia-inducible factor-1 (HIF-1) is involved in the regulation of hypoxiastimulated expression of monocyte chemoattractant protein-1 (MCP-1/CCL2) and MCP-5 (Cc112) in astrocytes. J Neuroinflammation 2007;4:12.

133. Van Der Voorn P, Tekstra J, Beelen RH, et al. Expression of MCP-1 by reactive astrocytes in demyelinating multiple sclerosis lesions. Am J Pathol 1999;154:45-51.

134. Tanuma N, Sakuma H, Sasaki A, Matsumoto Y. Chemokine expression by astrocytes plays a role in microglia/macrophage activation and subsequent neurodegeneration in secondary progressive multiple sclerosis. Acta Neuropathol 2006;112:195-204.

135. Huang D, Han Y, Rani MR, et al. Chemokines and chemokine receptors in inflammation of the nervous system: manifold roles and exquisite regulation. Immunol Rev 2000;177:52-67.

136. Babcock AA, Kuziel WA, Rivest S, Owens T. Chemokine expression by glial cells directs leukocytes to sites of axonal injury in the CNS. J Neurosci 2003;23:7922-7930.

137. Yan YP, Sailor KA, Lang BT, et al. Monocyte chemoattractant protein-1 plays a critical role in neuroblast migration after focal cerebral ischemia. J Cereb Blood Flow Metab 2007;27:12131224.

138. White FA, Sun J, Waters SM, et al. Excitatory monocyte chemoattractant protein-1 signaling is up-regulated in sensory neurons after chronic compression of the dorsal root ganglion. Proc Natl Acad Sci U S A 2005;102:14092-14097.

139. Gosselin RD, Varela C, Banisadr G, et al. Constitutive expression of CCR2 chemokine receptor and inhibition by MCP-1/CCL2 of GABA-induced currents in spinal cord neurones. J Neurochem 2005;95:1023-1034.

140. Gao YJ, Ji RR. c-Fos and pERK, which is a better marker for neuronal activation and central sensitization after noxious stimulation and tissue injury? Open Pain J 2009;2:11-7.

141. Thacker MA, Clark AK, Bishop T, et al. CCL2 is a key mediator of microglia activation in neuropathic pain states. Eur J Pain 2009:13:263-272.

142. Abbadie C, Lindia JA, Cumiskey AM, et al. Impaired neuropathic pain responses in mice lacking the chemokine receptor CCR2. Proc Natl Acad Sci U S A 2003;100:7947-7952.

143. Zhang J, Shi XQ, Echeverry S, et al. Expression of CCR2 in both resident and bone marrow-derived microglia plays a critical role in neuropathic pain. J Neurosci 2007;27:12396-12406.

144. Bhangoo S, Ren D, Miller RJ, et al. Delayed functional expression of neuronal chemokine receptors following focal nerve demyelination in the rat: a mechanism for the development of chronic sensitization of peripheral nociceptors. Mol Pain 2007;3:38.

145. Bhangoo SK, Ripsch MS, Buchanan DJ, Miller RJ, White FA. Increased chemokine signaling in a model of HIV1-associated peripheral neuropathy. Mol Pain 2009;5:48.
146. Ji RR, Gereau RWt, Malcangio M, Strichartz GR. MAP kinase and pain. Brain Res Rev 2009;60:135-148.

147. Jin SX, Zhuang ZY, Woolf CJ, Ji RR. p38 mitogen-activated protein kinase is activated after a spinal nerve ligation in spinal cord microglia and dorsal root ganglion neurons and contributes to the generation of neuropathic pain. J Neurosci 2003;23:4017-4022.

148. Tsuda M, Mizokoshi A, Shigemoto-Mogami Y, Koizumi S, Inoue K. Activation of p38 mitogen-activated protein kinase in spinal hyperactive microglia contributes to pain hypersensitivity following peripheral nerve injury. Glia 2004;45:89-95.

149. Weyerbacher AR, Xu Q, Tamasdan C, Shin SJ, Inturrisi CE. N-Methyl-d-aspartate receptor (NMDAR) independent maintenance of inflammatory pain. Pain 2010;148:237-246.

150. Migheli A, Piva R, Atzori C, Troost D, Schiffer D. c-Jun, JNK/ SAPK kinases and transcription factor NF-kappa B are selectively activated in astrocytes, but not motor neurons, in amyotrophic lateral sclerosis. J Neuropathol Exp Neurol 1997;56:1314-1322.

151. Obata K, Yamanaka H, Kobayashi K, et al. Role of mitogenactivated protein kinase activation in injured and intact primary afferent neurons for mechanical and heat hypersensitivity after spinal nerve ligation. J Neurosci 2004;24:10211-10222.

152. Daulhac L, Mallet C, Courteix C, et al. Diabetes-induced mechanical hyperalgesia involves spinal mitogen-activated protein kinase activation in neurons and microglia via N-methyl-D-aspartate-dependent mechanisms. Mol Pharmacol 2006;70:1246-1254.

153. Falsig J, Porzgen P, Lotharius J, Leist M. Specific modulation of astrocyte inflammation by inhibition of mixed lineage kinases with CEP-1347. J Immunol 2004;173:2762-2770.

154. Gao YJ, Ji RR. Chemokines, neuronal-glial interactions, and central processing of neuropathic pain. Pharmacol Ther 2010;126: $56-68$.

155. Katsura H, Obata K, Miyoshi K, et al. Transforming growth factor-activated kinase 1 induced in spinal astrocytes contributes to mechanical hypersensitivity after nerve injury. Glia 2008;56: $723-733$.

156. Ferrara N, Ousley F, Gospodarowicz D. Bovine brain astrocytes express basic fibroblast growth factor, a neurotropic and angiogenic mitogen. Brain Res 1988;462:223-232.

157. Eclancher F, Perraud F, Faltin J, Labourdette G, Sensenbrenner M. Reactive astrogliosis after basic fibroblast growth factor (bFGF) injection in injured neonatal rat brain. Glia 1990;3:502509.

158. Takano T, Oberheim N, Cotrina ML, Nedergaard M. Astrocytes and ischemic injury. Stroke 2009;40:S8-S12.

159. Hayakawa $\mathrm{K}$, Nakano $\mathrm{T}$, Irie $\mathrm{K}$, et al. Inhibition of reactive astrocytes with fluorocitrate retards neurovascular remodeling and recovery after focal cerebral ischemia in mice. J Cereb Blood Flow Metab 2010;30:871-882.

160. Borsello T, Clarke PG, Hirt L, et al. A peptide inhibitor of c-Jun $\mathrm{N}$-terminal kinase protects against excitotoxicity and cerebral ischemia. Nat Med 2003;9:1180-1186.

161. Davis JE, Gabler NK, Walker-Daniels J, Spurlock ME. The c-Jun $\mathrm{N}$-terminal kinase mediates the induction of oxidative stress and insulin resistance by palmitate and toll-like receptor 2 and 4 ligands in 3T3-L1 adipocytes. Horm Metab Res 2009;41:523530.

162. Ijaz A, Tejada T, Catanuto P, et al. Inhibition of C-jun N-terminal kinase improves insulin sensitivity but worsens albuminuria in experimental diabetes. Kidney Int 2009;75:381-388.

163. Oberheim NA, Takano T, Han X, et al. Uniquely hominid features of adult human astrocytes. J Neurosci 2009;29:3276-3287.

164. Oberheim NA, Wang X, Goldman S, Nedergaard M. Astrocytic complexity distinguishes the human brain. Trends Neurosci 2006; 29:547-553. 